\title{
Grammar Writing for a Grammar-reading Audience ${ }^{1}$ \\ Michael Noonan \\ University of Wisconsin-Milwaukee
}

1. INTRODUCTION: I'll begin this paper with a recitation of a set of familiar and depressing facts. Of the approximately 7000 languages spoken today, the following can be said with regard to demographics, all gleaned from the Ethnologue (Grimes 1996):

- fully $50 \%$ of the human race has as their first language one of just 10 languages;

- $52 \%$ are spoken by fewer than 10,000 people;

- $28 \%$ are spoken by fewer than 1,000 .

Longterm estimates concerning language vitality vary considerably, the most pessimistic being that of Michael Krauss (1992) who predicts that by the end of this century up to $95 \%$ of the world's languages will be moribund or extinct. The linguists associated with the Volkswagen Foundation's DOBES project opt for the rather more optimistic prediction that $60-70 \%$ of the world's languages will have died out by that time. Most everyone would probably agree that by the middle of this century, there will be less than 2000 languages spoken by integral communities, that is by communities in which both children and adults speak the language, and many of those languages will be changed in fundamental ways through contact with languages of national and global importance.

All of this would be discouraging enough if the world's languages were adequately documented. But here too the situation appears grave. We're confronted with the following, all of which are my [probably overly optimistic] estimates:

- we have full-scale grammars and dictionaries and abundant textual material for perhaps 500 languages;

- we have grammatical sketches or short grammars, and dictionaries for perhaps another 2000 languages - many of these are of poor quality;

- we have only rudimentary documentation [word lists, a few sentences, perhaps a paper on some aspect of the grammar] for another 2500 languages;

- we have little useful grammatical or lexical data for about 2000.

So, not only are most of the world's languages inadequately described, but given the rate at which languages are becoming moribund or extinct, we are engaged in a race against time [and against war, poverty, and the good and bad effects of globalization] to preserve as much of the world's linguistic heritage as possible.

In running this race, we face, among others, the following three major obstacles: the standard of grammar writing is not uniformly high, there is not a lot of funding to support grammar writing, and the profession does not sufficiently value or support the writing of grammars.

\footnotetext{
${ }^{1} \mathrm{I}^{\prime} \mathrm{d}$ like to thank Edith Moravcsik and an anonymous reviewer for helpful comments. In addition, I'd like to thank the linguists, named below, who provided me with their insights on grammar writing. Needless to say, all the shortcomings of this paper are mine alone.
} 
This paper will be concerned primarily with the first of these problems, namely the establishment of higher standards for grammar writing. As regards the second problem, funding, here have been many encouraging developments recently, and I will have nothing further to say about this issue. About the third issue, the evaluation of grammar writing within the profession and the professional support provided to grammar writers, I will make a few comments at the end of this talk.

2. STANDARDS FOR GRAMMAR WRITING - FULL-SCALE GRAMMARS: When you teach the craft of writing to students, one of the things you try to impress upon them is the importance of taking into account the audience to whom they are addressing their writing. The success of a piece of writing is usually measured by its reception. One has to know who will be reading the thing written and what their needs and expectations are in order to assess whether a work is successful.

Reference grammars have two sorts of audiences. The first consists of those who use a grammar to help them learn to speak or write the language described therein, and the second consists of those who consult a grammar to obtain information for typological or theoretical studies, i.e. professional linguists. The first sort of audience will most likely be learners of languages taught in formal classroom settings, languages which are used by people with political or economic power and which have significant literary traditions. Linguists, of course, may also be interested in obtaining information about these languages, but linguists are also likely to be interested in gathering information about languages which are not taught in formal classroom settings, which have little or no tradition of literary production, and which are not spoken by people with political or economic power - that is the great majority of the world's languages. In fact, the primary audience for the grammars of such languages are linguists, and those writing grammars of languages of this sort should write their grammars with the needs and expectations of professional linguists in mind.

One should also bear in mind that many of the grammars written in the next few decades will someday be the only sources of information about the languages they describe - not just for linguists, but also for the communities that currently speak them. The transition from vital, to moribund, to extinct can happen surprisingly quickly. For example, when I started working on the Nar-Phu language of Nepal in 1996, the language seemed quite vital - protected, it seemed, by the very hardships faced by the people who spoke it and the remoteness of their home region. By 2001, the young people had switched almost completely to the national language, Nepali, and when speaking Nar-Phu, many had difficulty recalling Nar-Phu words, in particular the special and distinctive honorific vocabulary, and were unable to produce the correct [i.e. historic] tones for many words they could recall. So, in preserving languages, it is important to record them not just before they die, but while they are still spoken by integral communities and while they still preserve that which made them distinctive representations of the human mind and spirit. The Nar-Phu that the younger generation will remember will not be the same language as that of their forebears. 
With all this as background, we should be aware that when we are writing grammars of those languages which will likely be moribund or extinct by the end of the century - that is, the great majority of the world's languages - that we are writing for the ages. So, we must make sure that what we are doing reaches for a very high standard.

What follows are a set of prescriptions for grammar writers intended to inform them about matters of form and content which would help make their grammars meet the needs and expectations of linguists and help give their grammars lasting value. In putting this list together, I consulted with a number of linguists - major users of grammars - who graciously took the time to contribute ideas on what a good grammatical description should be or should contain. These linguists are, in alphabetical order: Sasha Aikhenvald, Balthasar Bickel, Bernard Comrie, Bill Croft, Bob Dixon, Matthew Dryer, Mike Hammond, Martin Haspelmath, Larry Hyman, Ian Maddieson, Edith Moravcsik, and Randy LaPolla. Where one of the these linguists has suggested to me one of the points below, s/he is identified.

The list of twenty-eight dos and don'ts is organized informally into three general categories: 'user friendliness', 'descriptive adequacy', and 'comprehensiveness'.

\section{List of dos and don'ts for grammar writers}

USER FRIENDLINESS: MAKE YOUR GRAMMAR ONE THAT IS EASY TO USE AND OBTAIN INFORMATION FROM.

1. Where possible, avoid theory-specific terminology and use instead 'basic linguistic theory' as a source of terms: Experience has shown that grammatical theories have a short shelflife. Special terminology and notational conventions employed by new theories are appropriate for journal articles but not for grammars, which ought to have a shelflife longer than any given grammatical theory. Libraries are littered with virtually unusable grammars employing the very specialized conventions of extinct theories. Grammar writers should try, therefore, to write grammars for the broadest possible audience of linguists, employing only notational conventions and terms that trained linguists of any theoretical persuasion could reasonably be expected to understand, using terms drawn from what has recently come to be called 'basic linguistic theory'. Where new or theory-specific terms are introduced, they should be carefully defined. [DIXON, HAMMOND, HASPELMATH, MADDIESON, MORAVCSIK]

2. Provide a detailed index and table of contents: The index and table of contents of a grammar are important tools, especially useful when they are sufficiently detailed and properly organized. Though both serve to help grammar readers find information, they serve somewhat different functions. The index provides an alphabetical listing of topics, whereas the table of contents provides a schematic overview of the topics covered. The latter can be very important where the terms used by the grammar writer differ from those used by [or expected by] the grammar reader: the grammar reader may well find the information s/he needs quickly with a logically organized, detailed table of contents. In addition, in organizing an index, some con- 
ventions employed by Martin Haspelmath in his Lezgian grammar should be followed, namely noting in boldface type the main entry [or entries] for a given feature, and noting the absence of a given feature directly in the index with the dash. So, for example, one could indicate the absence of tone as follows: TONE: - . [BICKEL, COMRIE, CROFT, HASPELMATH]

3. The text should be divided into numbered and titled sections and subsections, and there should be ample cross-referencing within the text: Within the text itself, the following conventions make the text easier to use and should be encouraged: the text should be divided into numbered and titled sections and subsections, and, where appropriate, there should be crossreferencing between parts of the text where related issues are discussed; important terms should be highlighted by boldface type and/or by placing the terms in the margins; and finally, section numbers and/or titles should be placed in the margins as headers. [MORAvcsiK]

4. Provide plenty of examples: Properly glossed and translated examples are a necessary accompaniment to descriptive statements in all components of the grammar. Care should also be taken in the choice of examples: made-up sentences are appropriate for the presentation of information about basic grammatical structures, but examples should be drawn also from naturally occurring discourse. Further, the grammar writer should avoid using examples which are drawn from translations of foreign texts since such sentences may have been influenced by structures in the source language. [AIKHENVALD, MADDIESON]

5. Provide interlinear morpheme translations [glosses], as well as translations of the whole, for all examples: The necessity for this should be obvious, but too often this courtesy to the grammar reader is ignored or applied inconsistently. There should be a conveniently accessible list of all abbreviations and symbols used in morpheme glosses and all other parts the grammar and dictionary.

6. A typological sketch, consisting of no more than three to five pages, should be included at the beginning of the grammar: A short typological sketch is useful to the grammar reader because it helps the reader put the more detailed information contained in the grammar proper into appropriate context. The sketch should outline prominent features of the phonetics and phonology; should provide information about basic word order patterns, the presence of basic nominal and verbal inflectional categories, the presence of concord classes or classifiers, special lexical features, and so on; and should briefly describe if the language is head- or dependent-marking and if [and to what degree] the language exhibits properties of ergativity, inverse marking, split intransitivity, and so on. [AIKHENVALD]

7. The absence of a feature should be noted just as reliably as the presence of a feature: Too few grammars explicitly note the absence of commonly encountered grammatical features in the languages they are describing. Grammar readers cannot always be certain, therefore, whether the lack of discussion of a particular feature results from its absence in the language or from the fact that the grammar writer simply did not discuss the matter. Since the grammar writer cannot reasonably be expected to note the absence of any of the full set of possible grammatical features, s/he will have to 
choose carefully which features to note the absence of. The absence of any feature which might be expected on areal, genetic, or typological grounds should be noted [e.g. the absence of concord classes in a Bantu language or ejective consonants in a language of the Pacific northwest], as should features which are commonly encountered worldwide [e.g. tone]. [AIKHENVALD, BICKEL, COMRIE]

DESCRIPTIVE ADEQUACY: MAKE YOUR GRAMMAR ONE IN WHICH TOPICS ARE DESCRIBED IN ADEQUATE DETAIL, IN A MANNER THAT REVEALS IMPORTANT GENERALIZATIONS, AND WITH ADEQUATE BACKING.

8. The grammar writer should prepare him/herself by obtaining a good background in general typology and the linguistics of the relevant language family: A sound background in general typology is imperative for grammar writers; it is also important for the grammar writer to acquire a sound knowledge of the linguistics of the relevant language family and/or speech area and to consult works dealing the typology of features prominent in the language under investigation [e.g. works on ergativity for works on languages exhibiting ergative structures, works on classifier systems for languages having classifier systems, etc.]. [AIKHENVALD, LAPOLLA, MADDIESON]

9. In explaining phonetics, standard IPA characters should be used: Standard IPA phonetic symbols, not 'practical orthography' symbols [even where these are sanctioned by tradition for a given speech area or language family], should be used in presenting information about the phonetics of a language. Even when IPA symbols are used, they should be accompanied by a statement describing their value [which could be done by reference to a standard work such as the IPA Handbook]. When non-IPA characters are introduced for use in the practical orthography for the language, their relation to the IPA characters used to describe the phonetics should be made transparent. [HAMMOND, MADDIESON]

10. To the degree possible, detailed instrumental documentation of the phonetics should accompany descriptive statements: Descriptive statements of the phonetics of a language should be accompanied by instrumental documentation of at least the following features: acoustic characterization of vowels in formant space, measurement of the acoustic durations of vowels and consonants in a controlled set of data [so that some aspects of the duration patterns of the language can be quantitatively described], and for tone or pitch accent systems the shapes of F0 patterns associated with the contrasts. Any typologically unusual phonetic features should be described together with appropriate instrumental documentation. [HAMMOND, MADDIESON]

11. Provide a full description of the segmental and suprasegmental contrasts and an explanation of the basis for arriving at them: A grammar should contain a full description of the segmental contrasts and an explanation of the basis for arriving at the analysis. In particular, the analysis must demonstrate contrast between segments [in the form of minimal pairs] and present arguments in favor of [or against] the unitary vs sequential analysis of complex elements. In addition, the analysis must include careful descriptions of suprasegmental contrasts: tone [if phonemic], stress, and intonation. 
Intonation and stress may have implications for morphology and syntactic structure. [MADDIESON]

12. Provide a description of distributional patterns of the elements of the phonology: A grammar should contain a discussion of the basic distributional patterns of the elements of the phonology in terms of syllables, words, and any other units which seem to control, or be marked by, different distributional possibilities. Minimally, canonical syllable structure, possible onsets and codas, and nucleus-margin restrictions should be described. [MADDIESON]

13. Provide full paradigms showing combinations of all relevant morphemes, not just lists of affixes: In morphologically complex languages, full paradigms, arranged in some accessible form [e.g. as tables] should be provided and not just a list of the affixes. When the language has complex morphophonemic processes, there should be a sufficient number of paradigms provided to illustrate the various combinatorial possibilities. [HYMAN]

14. Define grammatical categories used in the grammar: When using grammatical category labels, the grammar writer should make clear what grammatical tests are being used to define those categories. This applies especially to labels for grammatical roles [e.g. subject, direct object, etc.] and word classes [e.g. adverb, adjective, etc.]. [AIKHENVALD, CROFT]

15. The choice of labels for grammatical features is not as important as a thorough presentation of the facts: Grammar writers should not worry too much about whether a label for a given feature is the most apt. More important is a thorough description of the phenomenon. [CROFT, HASPELMATH, LAPOLLA]

16. It's better to admit ignorance about a grammatical feature than to say nothing: Saying nothing about a particular grammatical feature leaves the matter open to incorrect interpretations, for example that the feature does not exist in the language. When the grammar writer lacks sufficient information about an issue, s/he should not be afraid to admit this, using perhaps a statement like the following: 'There is insufficient data at this time to determine conditions under which this form is used.' Further, it is important to emphasize that grammar writers should present data about grammatical phenomena that their theories either cannot account for or are not concerned with: technical papers in journals can be narrow in their scope, but reference grammars must endeavor to describe the entire language system. [COMRIE, HAMMOND, HASPELMATH]

17. Existential statements are not sufficient: In writing grammars, it is not sufficient simply to note that the language has some feature $X$; one must also describe under what conditions that feature is used. For example, noting that Chantyal has a plural suffix $-m a$ and then limiting the discussion to a few examples is not enough: an adequate description will also say under what conditions the suffix must be used and under what conditions it cannot be used. [HASPELMATH]

18. Indications of frequency should be provided where appropriate: Indications of the frequency of grammatical constructs can provide useful information. These include segmental frequency counts [based on texts or the lexicon] and indications of 
whether a given morphological or syntactic feature is rare or marginal [e.g. lexically limited]. [BICKEL, MADDIESON]

19. In general, it's best to describe morphology with a form-to-function orientation and syntax with a function-to-form orientation: It's probably impossible [or at least impractical] to write a grammar which is exclusively form-to-function [as the Bloomfieldians attempted in principle] or function-to-form [as Comrie-Smith grammars attempted in principle]. The best compromise seems to be to write the morphology primarily form-to-function and the syntax primarily function-to-form. The reason for this arrangement is that form is very easy to recognize in morphology, but is rather less so in syntax. This does not mean that function-to-form should be entirely absent from the morphology, nor form-to-function from syntax. For example, alongside a formto-function discussion of the meanings of verbal affixes, it would also be useful to have a function-to-form discussion of TAM categories, describing how they are expressed in the language. And in syntax, in addition to function-to-form chapters on nominal modification, interrogation, expression of negative senses, etc, it would also be very useful to have a form-to-function chapter on the uses of various word order possibilities. [HASPELMATH]

20. A vocabulary consisting of all the lexemes which occur in the grammar is a necessary component of a good grammar: Grammatical descriptions longer than a sketch should contain a vocabulary consisting of all the lexemes used in the grammar and accompanying texts. These lexemes should be properly labeled for word class or concord class [if appropriate] and, for grammatical morphemes, there should be an indication of the section in the text where the item is discussed. Where variant forms of a lexical item are found in the grammar and texts, the variants should be noted in the vocabulary. [DIXON, AIKHENVALD]

21. A good collection of texts should be included with the grammar: A good collection of texts with morpheme glosses and translations is of great importance for a successful grammar. The texts provide illustrations of the constructions described in the grammar, but unlike the examples in the grammar itself, textual examples show the constructions in context. Further, grammar writers cannot be expected to write about, or even know about, all possible grammatical constructions. A good collection of texts can permit later analysts to gather information about constructions that the grammar writer, for whatever reasons, did not discuss or did not discuss in much detail. There should be at least twenty to thirty pages of texts. [DIXON]

COMPREHENSIVENESS: MAKE YOUR GRAMMAR ONE WHICH IS COMPREHENSIVE IN SCOPE.

22. The grammar writer should consult survey questionnaires and well-regarded grammars to make sure that important topics are not missed: The most detailed survey questionnaire that is generally available is the Comrie-Smith [Lingua Descriptive Series] questionnaire, which has formed the basis for a number of grammars. This function-to-form questionnaire [see above] can be profitably consulted by the grammar writer, as can well-regarded grammars, of which several lists are available. [COMRIE, DRYER, LAPOLLA] 
23. The grammar should contain information about genetic and areal affiliations of the language: A description of the genetic affiliation of the language should be provided, along with information about the linguistic area and possible areal influences, where such information is known. This can be fairly brief unless there are special issues to be discussed [e.g. controversies concerning genetic affiliation]. [AIKHENVALD]

24. The grammar should contain information about the sociolinguistic context: There should be a short description of demographic and socio-cultural facts relating to the language being described, including the number and geographical distribution of speakers, the demographics of language use [e.g. whether the language is spoken only by adults and not children], the degree and nature of multilingualism in the speech community, and the degree of literacy and access to education. In addition, the author should reveal how data about the language was obtained and should provide information about the native speakers who served as language consultants.

25. Grammars should contain ample references to previous scholarship on the language and its culture: The bibliography should contain ample references to previous scholarship on the language; if the language has not been the subject of much previous scholarship, the list of references should be comprehensive. Previous scholarship on the culture of the speakers of the language should also be noted.

26. Grammars should contain good descriptions of the phonetics and the phonology, as well as of the morphology and the syntax: Some grammars include little more than a list of phonemic or 'practical orthography' symbols and only a brief description of the phonology with just a few examples. Proper descriptions of the phonetics and the phonology of a language are just as important to the success of a grammar as proper descriptions of the morphology and syntax. And here too there should be a plenitude of examples, narrowly transcribed. [HAMMOND, HYMAN, MADDIESON]

27. A good dictionary is an powerful adjunct to a good grammar: As noted, vocabularies, consisting minimally of the lexical items employed in the grammar, should be included with any grammatical description longer than a sketch. The existence of such a vocabulary, however, does not diminish the value of a good, full-scale dictionary, which, apart from any other uses it may have, is also a powerful adjunct to a grammar. A good dictionary comes with lots of example sentences from which a great deal of useful grammatical information can be gleaned even about topics that the grammar writer/dictionary creator has no knowledge of or interest in. For example, very few grammars, even good grammars, contain much information about clausal complementation. Typically there will be discussions of complement-types with some example sentences that hint at the distribution of these forms, but very rarely will the grammar contain much explicit discussion on the distribution of complement-types vis-à-vis complement-taking predicates, or contain a sufficiently large number of examples to allow the analyst to infer the distribution. A good dictionary, on the other hand, can be a goldmine of information about such topics.

28. Where practical, audio and video recordings should be made of various language genres: Where practical, audio and video recordings of a variety of language genres and cultural activities should be made. A subset of these should be annotated, provided 
with appropriate commentary, and deposited in an archive where they may be studied by scholars. [A number of such archives are now in existence.] Further, photographs and drawings can be very useful in documenting information about cultural artifacts, the natural environment, and botanical and zoological vocabulary.

Points 27 and 28 are desiderata rather than requirements for successful grammars. However, with regard to point 28, it's well to keep in mind that over the years the materials to be included in 'good' grammars, i.e. ones that would fully meet the highest expectations of their day, have progressively expanded with advances in the field and in technology. At this time, we can't anticipate the degree to which, say, intonational information, ordinarily not transcribed in published discourses, will be considered crucial to syntactic analysis. It's best to archive audio and visual records of speakers, if at all feasible.

Needless to say, not everything that a grammar should contain is noted in the points above since the list focuses mostly on those things that are left out or not done with some regularity. This accounts for the fact that the prescriptions relating to phonetics and phonology are much more specific than those for morphology and syntax, reflecting the generally lower standards of training of field linguists in phonology and, in particular, phonetics.

The standard of grammar writing detailed above is raises a pretty high bar, and $I^{\prime} m$ the first to admit that a grammar can be very useful and still not conform to all of the prescriptions listed. However, the more that are observed, the more useful the grammar will be.

3. STANDARDS FOR GRAMMAR WRITING - SKETCHES AND SHORT GRAMMARS: The list of dos and don'ts already given applies, of course, only to full-scale reference grammars and not to grammar sketches, which necessarily will fail to conform to many of the prescriptions on the list, in particular those placed under 'descriptive adequacy' and 'comprehensiveness'. Grammar sketches and short grammars have, of course, a legitimate function. In a perfect world, we would have full-scale grammars for every language, and grammar sketches would serve as convenient summaries of the facts. In our very imperfect world, often all we have for many languages - and maybe all we will ever have - is a sketch or short grammar. These shorter works, then, should be prepared with the same care as full-scale grammars. Of the list of dos and don'ts, the following are applicable even to sketches and short grammars. The numbering of the prescriptions is preserved from the original list:

USER FRIENDLINESS

1. Where possible, avoid theory-specific terminology and use instead 'basic linguistic theory' as a source of terms.

2. Provide a detailed index and table of contents.

3. The text should be divided into numbered and titled sections and subsections, and there should be ample cross-referencing within the text.

4. Provide plenty of examples. 
5. Provide interlinear morpheme translations [glosses], as well as translations of the whole, for all examples.

7. The absence of a feature should be noted just as reliably as the presence of a feature. DESCRIPTIVE ADEQUACY

8. The grammar writer should prepare him/herself by obtaining a good background in general typology and the linguistics of the relevant language family.

9. In explaining phonetics, standard IPA characters should be used.

11. Provide a full description of the segmental and suprasegmental contrasts and an explanation of the basis for arriving at them.

12. Provide a description of distributional patterns of the elements of the phonology.

13. Provide full paradigms showing combinations of all relevant morphemes, not just lists of affixes. [applies to short grammars, not sketches]

14. Define grammatical categories used in the grammar.

15. The choice of labels for grammatical features is not as important as a thorough presentation of the facts.

16. It's better to admit ignorance about a grammatical feature than to say nothing.

18. Indications of frequency should be provided where appropriate.

19. In general, it's best to describe morphology with a form-to-function orientation and syntax with a function-to-form orientation. COMPREHENSIVENESS

22. The grammar writer should consult survey questionnaires and well-regarded grammars to make sure that important topics are not missed.

23. The grammar should contain information about genetic and areal affiliations of the language.

24. The grammar should contain information about the sociolinguistic context.

25. Grammars should contain ample references to previous scholarship on the language and its culture.

Of the twenty-eight prescriptions on the list, all but 6, 10, 17, 20, 21, 26, 27, and 28 apply to sketches and short grammars as well; 13 applies to short grammars, but not necessarily sketches. Needless to say, the more of these additional features are incorporated into a grammar or even a sketch, the more useful the it will be.

4. COMMUNITY SUPPORT: I'll close with a few remarks on how the community of linguists can support grammar writing.

Among professional linguists, grammar writing is subtly discouraged by the way in which grammars are evaluated for purposes of hiring, tenure, and promotion. At research universities in particular, published articles on theoretical matters are valued more highly than published grammars or grammar sketches. Professional organizations could help change this situation by, for example, raising awareness among linguists concerning the urgent need for grammar writing at this time and by encouraging grammars as topics for dissertations. The latter could be accomplished by the creation of special dissertation fellowships for grammar writing and by skewing the selection criteria for existing dissertation fellowships in favor of grammar writing. Professional 
organizations such as the LSA or ALT could also establish awards for the best published grammar of the year, thereby raising the profile of grammar writers.

Further, the community of linguists could provide support for grammar writing through the establishment of consultancy services for qualified grammar writers. This service is of greatest importance in the area of phonetics, where the standard of training throughout the profession is probably the lowest among those skills that are required for writing grammars.

Finally, online publication of grammars and dictionaries has a number of advantages over paper publication: online grammars and dictionaries can easily be updated and revised, thereby increasing the likelihood that they will conform to the prescriptions discussed earlier. They can also be made available to a wider audience [especially if access is free] than is possible with paper publication. And lastly, online, or at least electronic, publication can facilitate the addition of audio and visual materials to the written text of the grammar.

There are two problems with online publication. The first is that, in many cases, it is not evaluated as highly as paper publication for purposes of hiring, tenure, and promotion. If the venues for online publication meet the same standards as high quality paper publication - that is, meet high standards of editorial review - then they should be evaluated equally. Again, professional organizations have a role to play here in encouraging academic departments to accept high quality online publication. ${ }^{2}$ The second problem relates to the relative impermanence of electronic and online publication media. Here too, professional organizations can play a role in arranging for the archiving of grammars published electronically in longer-lived formats.

\section{References:}

Grimes, Barbara F. et al. 1996. Ethnologue. Dallas: SIL International. Krauss, Michael. 1992. 'The world's languages in crisis.' Language 68.1:4-10.

\footnotetext{
${ }^{2}$ Online publication has a number of virtues, but it also poses a number of challenges both for academic departments evaluating candidates for hiring, promotion, performance raises, and so on and for editorial boards. For example, one of the virtues of online publication is that it allows for easy revision of texts. For editorial boards, a question arises as to how much revision should be allowed, how it should be monitored, and how much revision is allowable before the work must be reviewed again. Different standards might well be applied to journal articles and reference works such as grammars. In the case of grammars, I would suggest a fairly liberal standard for revision, drawing the line at changes that affect the framework or mode of analysis. In such cases, the revised grammar would have to undergo another review process.
} 